\title{
OS CERAMISTAS NA PAISAGEM PAULISTA: UMA PROPOSTA METODOLÓGICA
}

\author{
Autor: Glauco Constantino Perez ${ }^{1}$ \\ Coautora: Marisa Coutinho Afonso ${ }^{2}$
}

\section{Resumo}

Este artigo apresenta o método de pesquisa utilizado durante um levantamento de dados feito para a construção de um banco de dados (BD) que tem sido utilizado para o projeto de doutorado do autor. $\mathrm{O}$ BD tem por intuito ser fonte para a construção de mapas georreferenciados onde se possam observar zonas de contato e fronteiras entre as populações ceramistas que ocupavam a região entre as Bacias dos rios Tietê e Paranapanema, ao sul do Estado de São Paulo. Informações preliminares levantadas até o momento indicam a existência de 728 sítios arqueológicos em que foram identificadas cerâmicas Tupi e Jê. A discussão da gestão do patrimônio arqueológico poderá ser debatida já que esta pesquisa tem como intuito também a proposição de uma nova maneira de organização e disponibilização dos dados arqueológicos.

Palavras-chave: Arqueologia paulista, ceramistas, Tupi, Jê, gestão de patrimônio arqueológico.

\section{Abstract}

This article presents the research method used for a data collection used for the construction of a database that has been used for the author's PhD. The database is meant to be a source for the construction of georeferenced maps, where you can observe contact zones and boundaries between ceramic populations that occupied the region between the basins of the rivers Tietê and Paranapanema, south of São Paulo state. Preliminary data indicate the existence of 728 archaeological sites where Tupi and Jê ceramics have been identified. Archaeological heritage management is discussed in this research.This research has the intention also to propose a new way of organization and availability of archaeological data.

\footnotetext{
${ }^{1}$ Doutorando em Arqueologia no Museu de Arqueologia e Etnologia -MAE/USP e pesquisador do Laboratório de Arqueologia, Etnologia e Etnohistória da Universidade Estadual de Maringá LAEE/UEM. Bolsista CNPq.

MAE/USP: Avenida Professor Almeida Prado, 1466 - Butantã, São Paulo - SP, CEP 05508-070. glauc01113@usp.br-fone: 113091-4906

${ }^{2}$ Professora Doutora do Museu de Arqueologia e Etnologia - MAE/USP e coordenadora do Laboratório de Arqueologia da Paisagem e Geoarqueologia do MAE/USP - LAPGEO, : bolsista de produtividade do CNPq.

MAE/USP: Avenida Professor Almeida Prado, 1466 - Butantã, São Paulo - SP, CEP 05508-070. marisa.afonso@usp.br-fone: 11 3091-2885
}

(C) Rev. Arqueologia Pública

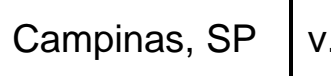
No.() p.13-21 /2015 ISSN 2237-8294 
Keywords: São Paulo Archaeology, Ceramic groups,Tupi, Jê, archaeological heritage management.

\section{Résumé}

Cet article présente la méthode de recherche utilisée pour une enquête de données pour la construction d'une Base de Données (BD) qui est utilisée pour le projet de doctorat de l'auteur. La BD est une source pour la construction de cartes géoréférencées où on peut observer zones de contact et frontières entre populations céramistes qui occupaient la région entre les bassins des fleuves Tietê et Paranapanema, au sud de l'État de São Paulo. Des informations préliminaires recueillies à ce jour indiquent l'existence de 728 sites archéologiques céramiques qui ont été identifiés comme Tupi et Jê. La discussion de la gestion du patrimoine archéologique est faite parce que cette recherche a l'intention également de proposer un nouveau mode d'organisation et de disponibilité des données archéologiques.

Mots-clés: Archéologie de São Paulo, céramistes, Tupi, Jê, Gestiondupatrimoinearchéologique..

v. No.() 


\section{Introdução}

Neste artigo apresentaremos um método de pesquisa utilizado durante a criação de dados para o projeto de doutorado do autor. A pesquisa tem por objetivo construir um Banco de Dados (BD) suficientemente denso para contribuir na construção de mapas georreferenciados para estudar a distribuição dos sítios ceramistas pela paisagem. Essa proposta busca entender as áreas de contato entre os grupos pré-históricos da região entre as bacias dos rios Tietê e Paranapanema - sul do Estado de São Paulo, em um conjunto que se estabelecem constantes contatos intergrupais.

Este método tem sido utilizado por diversos pesquisadores nos estados de Minas Gerais (DELFORGE, 2010), Mato Grosso do Sul (KASHIMOTO, 2009) e Paraná ${ }^{3}$ (SOUZA, J. MERENCIO, F., 2013), como apontaremos a seguir e demonstra ser bastante conclusivo, embora exija pesquisa bibliográfica bastante intensa, aglomerando dados de diversas fontes e diversos arquivos e bibliotecas. Para esta pesquisa as bibliotecas de empresas de arqueologia preventiva, a Biblioteca do Museu de Arqueologia e Etnologia da Universidade de São Paulo e o Arquivo do Instituto do Patrimônio Histórico e Artístico Nacional - Superintendência de São Paulo (IPHAN/SP) foram abordadas.

Os resultados preliminares obtidos para esse levantamento também serão apresentados de maneira resumida neste trabalho, pois a busca de fontes, especialmente nos Arquivos do IPHAN/SP, não foram concluídos. Além disso, chamaremos a atenção para o fazer arqueológico atual, as dificuldades enfrentadas durante os levantamentos e também uma sugestão para gestão do patrimônio arqueológico brasileiro, já que esse método permite a organização e melhor observação de modo geral dos dados.

\section{O método utilizado}

${ }^{3}$ MOTA, 2010. V Fórum de Pesquisa e Pós-Graduação em História \& XVI Semana de História da Universidade Estadual de Maringá em uma mesa redonda intitulada 'Populações tradicionais: indígenas, quilombolas e faxinalenses - Populações indígenas no Paraná' em outubro de 2010.

(C) Rev. Arqueologia Pública

\begin{tabular}{l|l} 
Campinas, SP & $\mathrm{v}$.
\end{tabular}

No.()

\begin{tabular}{l|l} 
p.13-21 & $/ 2015$
\end{tabular}

ISSN 2237-8294 
O método aplicado para a construção do Banco de Dados (BD) consiste em aglomerar e cruzar dados provindos de diversas fontes secundárias produzidas a partir dos estudos feitos em trabalhos de campo. Esta pesquisa procura organizar e agrupar informações sobre sítios cerâmicos que ainda estão dispersas, contribuindo para a produção de conhecimento sobre a arqueologia regional.

O que se busca com essa pesquisa é unir dados de trabalhos arqueológicos realizados pontualmente para que possamos ter uma visão geral dos avanços e o atual estado da arqueologia relacionada às populações ceramistas no sul do Estado de São Paulo, já que nesta região, conforme a bibliografia indica, é região de contato entre diversas populações (AFONSO, 2015, SCATAMACCHIA, 2008, CORREA, 2014). Dessa maneira, as fontes utilizadas para esta pesquisa são: livros, teses, dissertações, relatórios de empresas de contrato, banco de dados online do Cadastro Nacional de Sítios Arqueológicos (CNSA), o acervo impresso do CNSA, disponível na Superintendência de São Paulo e, principalmente, publicações realizadas a respeito dessa temática em revistas.

Nesse sentido, a visita aos arquivos e bibliotecas tem sido frequentes durante $O$ processo de aglutinação dos dados. A seguir apresentamos rapidamente os arquivos, bibliotecas e acervos consultados para o levantamento dos dados:

-Acervo das Bibliotecas de empresas de consultoria;

-Banco de dados do Cadastro Nacional de Sítios Arqueológicos (CNSA) online; -Arquivo do Instituto do Patrimônio Histórico e Artístico Nacional (IPHAN/São Paulo):

-Arquivo de Fichas do CNSA impressas;

-Arquivo de Projetos e Relatórios de arqueologia preventiva (em andamento);

-Acervo da Biblioteca do Museu de Arqueologia e Etnologia MAE/USP:

-Livros;

-Teses;

-Dissertações;

-Publicações:

-Revista do Museu Paulista;

-Arquivos do Museu Paranaense (Séries de Antropologia, Arqueologia e Etnologia); 
-Anhembi;

-Revista do CEPA;

-Revista de Arqueologia/Sociedade de Arqueologia Brasileira - SAB;

-Revista do Museu de Arqueologia e Etnologia;

Até o momento não foi possível concluir a pesquisa dentro do Arquivo de projetos e Relatórios produzidos pelas empresas de arqueologia preventiva, embora acreditamos que 0 término da pesquisa no IPHAN irá suprir essa carência dos dados. Lembramos que apesar do encerramento do levantamento para a construção do BD, muitas outras fontes são produzidas e o ano de 2013 foi escolhido para ser a deadline para a inclusão dos dados colhidos no IPHAN, embora publicações e dados disponíveis na Biblioteca do Museu de Arqueologia e Etnologia da USP ainda são levantados e inseridos no BD.

Dessa maneira, enfrentar a bibliografia extensa, com uma grande quantidade de sítios arqueológicos, informações repetidas ou principalmente faltantes, causadas pela falta de padronização das informações oferecidas pelos pesquisadores, como: localização do sítio municípios, coordenadas geográficas, e fundamentos conceituais e metodológicos dos arqueólogos envolvidos nas pesquisas, datações inexistentes ou confusas; são desafios constantes da lida com esse tipo de pesquisa.

\section{O Bando de Dados (BD)}

O Banco de Dados (BD) foi criado no software Microsoft Office Access (2010), que é um sistema de gerenciamento de banco de dados da Microsoft, que combina o Microsoft Jet DatabaseEngine com uma interface gráfica do utilizador (graphicaluser interface). Ele permite o desenvolvimento rápido de aplicações (RAD -RapidApplicationDevelopment) que envolve tanto dados, como também uma interface a ser utilizada pelos usuários. A tabela do banco é constituída por linhas que representam os sítios arqueológicos e por colunas que indicam

características dos sítios. O programa oferece ainda a possibilidade da construção de um formulário base para a observação dos dados.

( Rev. Arqueologia Pública

Campinas, SP $\quad$ v.

No.()

p.13-21 $/ 2015$

ISSN 2237-8294 
O BD foi inspirado nas categorias elencadas no Cadastro Nacional de Sítios Arqueológicos (CNSA), embora algumas características foram modificadas e adequadas para as condições atuais dos sítios, como por exemplo inserimos espaços para maiores informações relacionadas às datações, mais espaço para o campo de Coordenadas geográficas (UTM e por grau, minuto e segundo) e também maior espaço para uma segunda referência bibliográfica associada a cada sítio.

Além disso, a ordem das colunas de características está distribuída em três eixos: Descrição geral (município atual; município registrado; sigla do sítio - IPHAN; sigla do sítio Autor; nome do sítio; tradição; datação existente; informações datação/amostra), Distribuição espacial e física (categoriaspré-colonial/contato; componentes (unicomponencial/multicomponencial); deposição (superfície/profundidade); exposição (céu aberto/abrigo); dimensões $\left(\mathrm{m}^{2}\right)$; unidade morfológica; compartimento topográfico (topo, terço superior, inferior, planície de inundação); DATUM; Zona; longitude $(\mathrm{E})$; latitude $(\mathrm{N})$; coordenada em grau, minuto e segundo), e por fim, Referências bibliográficas ( $n^{\circ}$ CNSA; localização dos dados; referência bibliográfica associada; informações extra/observações; segunda referência bibliográfica). Esse layout do banco de dados favorece o entendimento desses eixos como um todo, já que as informações são bastante complementares entre as colunas; no total são 25 categorias descritivas elencadas para cada sítio arqueológico.

\section{Dados parciais da pesquisa}

Como o BD consta com muitas variáveis, apresentaremos apenas as variáveis de maior destaque para a pesquisa, já que a intenção principal do trabalho é descortinar a quantidade de sítios dessa região e quais deles são de grupos ceramistas Tupi e quais são dos ceramistas Jê. A grande surpresa para este trabalho foi o grande aparecimento de sítios arqueológicos sem uma tradição ceramista definida. Muitas vezes as cerâmicas são analisadas, descritas, mas uma caracterização etnográfica é deixada de lado pelos pesquisadores responsáveis. Essa variável abre espaço para uma discussão metodológica que não abordaremos.

(c) Rev. Arqueologia Pública

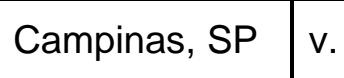

No.()

p.13-21 $/ 2015$

ISSN 2237-8294 
$\mathrm{O} \mathrm{BD}$, até o momento, conta com um total 743 sítios cadastrados, para o espaço delimitado para a pesquisa, sendo que são 449 sítios Tupi, 192 sítios Jê, 97 sítios sem referência à uma tradição associada e 5 sítios que são classificados com as duas tradições Tupi e Jê.

Sítios arqueológicos Tupi que apresentam datas são 52 apenas, 256 com coordenadas geográficas e que apresentam ambas as informações são apenas 32. Dos sítios Jê; 10 apresentam datações, 64 coordenadas geográficas e apenas cinco tem as duas características.

Dos sítios que tem material Tupi e Jê o único que apresenta datação não tem coordenada geográfica e os 4 que são georreferenciados não têm uma datação estipulada. Dos sítios que não apresentam ligação a uma tradição específica dois têm datações, 43 coordenadas geográficas, mas inexistem sítios com as duas características correlacionadas.

Dessa maneira, de um universo com 743 sítios, 65 datações, ou melhor, 8,75\% dos sítios apresentam datações conhecidas, 367 coordenadas são apresentadas, isto é 49,39\% dos sítios estudados têm sua referência geográfica; e apenas 37 sítios, ou 4,9\% deles têm as duas características.

\section{Conclusão}

O trabalho aqui apresentado tem por objetivo compreender e sugerir a maneira como acontece a distribuição dos sítios cerâmicos pela paisagem atenta também para a aglomeração de dataçõespara compreender a ocupação do espaço, observar padrões de assentamento, delimitar possíveis fronteiras étnicas e agregam modelos de explicações da ocupação regional e fontes secundárias arqueológicas produzidas ao longo dos últimos 50 anos de pesquisas no Estado de São Paulo.

Esse Bando de Dados denso será capaz de oferecer subsídios para a identificação de uma paisagem arqueológica a fim de compreender a dinâmica de ocupação do sul do Estado de São Paulo e dessa maneira questionar o fazer arqueológico, em uma perspectiva da arqueologia pós-processualista em que sejam possíveis a novas formas de simulação e reconstituição das ocupações humanas e de suas interações culturais no espaço. Além disso,

(c) Rev. Arqueologia Pública

\begin{tabular}{l|l} 
Campinas, SP & $\mathrm{v}$.
\end{tabular}

No.()

\begin{tabular}{l|l} 
p.13-21 & $/ 2015$
\end{tabular}

ISSN 2237-8294 
a construção de um banco de dados que inclui as citações de procedência dos dados pode ser uma alternativa de sistematização, organização e gestão de dadossimplificada de maneira virtual, bem como a simplificação da divulgação aos interessados.

\section{Agradecimentos}

Agradecemos à CAPES/CNPq pelo auxílio financeiro para a Pesquisa; ao Professor Dr. Lúcio Tadeu Mota da Universidade Estadual de Maringá - UEM/PR pela coorientação da pesquisa; Scientia Consultoria Científica pela cessão de relatórios;Ao IPHAN/SP nas pessoas de Rafael Oliveira e Júlio César de Oliveira; equipe de funcionários da Biblioteca MAE/USP.

\section{Referências bibliográficas}

AFONSO, M. C. Um olhar para a arqueologia pré-histórica do Estado de São Paulo. Livre docência. MAE/USP, São Paulo, 2005.

CORREA, A. A. Pindorama de Mboîa e l̂akaré: continuidade e mudança na trajetória das populações Tupi. Tese de doutorado. MAE/USP, 2014.

DELFORGE, A. O gerenciamento do patrimônio arqueológico no estado de Minas Gerais utilizando-se sistema de informações espaciais (SIG), Mestrado. PUC-MG, Belo Horizonte, 2010.

KASHIMOTO, E. M. Arqueologia do leste de Mato Grosso do Sul. I Encontro de arqueologia de MS. Campo Grande. Um Arq. 2009.

( Rev. Arqueologia Pública

Campinas, SP

v. No.() 
SCATAMACHIA, M. C. M. Considerações sobre a distribuição das sociedades tribais de filiação linguística tupi-guarani no estado de São Paulo. IN: PROUS, A.; LIMA, Tânia Andrade. Ceramistas Tupiguarani. 2008. p. 117-147.

SOUZA, J. \& MERENCIO, F. A diversidade dos sítios arqueológicos Jê do Sul no Estado do Paraná. Cadernos do LEPAARQ - Textos de Antropologia, Arqueologia e Patrimônio. V. X, n²0. Pelotas, RS: Editora da UFPEL, 2013.

V. p.13-21 $/ 2015$ 